\title{
pH-Responsive Polysaccharide-Based Polyelectrolyte Complexes As Nanocarriers for Lysosomal Delivery of Therapeutic Proteins
}

\author{
Marina I. Giannotti, ${ }^{*,+,, \S}$ Olga Esteban, ${ }^{+, \|}$Mireia Oliva, ${ }^{+, \perp}$ María F. García-Parajo, ${ }^{+, \|, \#}$ and Fausto Sanz ${ }^{*,+, \neq, \S}$ \\ ${ }^{\dagger}$ CIBER de Bioingeniería, Biomateriales y Nanomedicina (CIBER-BBN), Zaragoza, 50018, Spain \\ ${ }^{\ddagger}$ Physical Chemistry Department, University of Barcelona (UB), Martí i Franquès 1-3, Barcelona,08028, Spain \\ ${ }^{\S}$ Nanoprobes \& Nanoswitches Group and "BioNanoPhotonics Group, Institute for Bioengineering of Catalonia (IBEC), \\ Baldiri i Reixac 15-21, Barcelona, 08028, Spain \\ ${ }^{\perp}$ Pharmaceutical Technology Unit, School of Pharmacy, University of Barcelona (UB), Av. Joan XXIII s/n, Barcelona, 08028, Spain \\ \#ICREA-Institució Catalana de Recerca i Estudis Avançats, Barcelona, 08010, Spain
}

Supporting Information

ABSTRACT: Nanopharmaceutics composed of a carrier and a protein have the potential to improve the activity of therapeutical proteins. Therapy for lysosomal diseases is limited by the lack of effective protein delivery systems that allow the controlled release of specific proteins to the lysosomes. Here we address this problem by developing functional polyelectrolytebased nanoparticles able to promote acidic $\mathrm{pH}$-triggered release of the loaded protein. Trimethyl chitosan (TMC) was synthesized and allowed to form polyelectrolyte complexes (PECs) with the lysosomal enzyme $\alpha$-GAL through self-assembly and ionotropic gelation, with average particle size $<200 \mathrm{~nm}$, polydispersity index $(\mathrm{PDI})<0.2, \zeta$ potential of $\sim 20 \mathrm{mV}$, and a

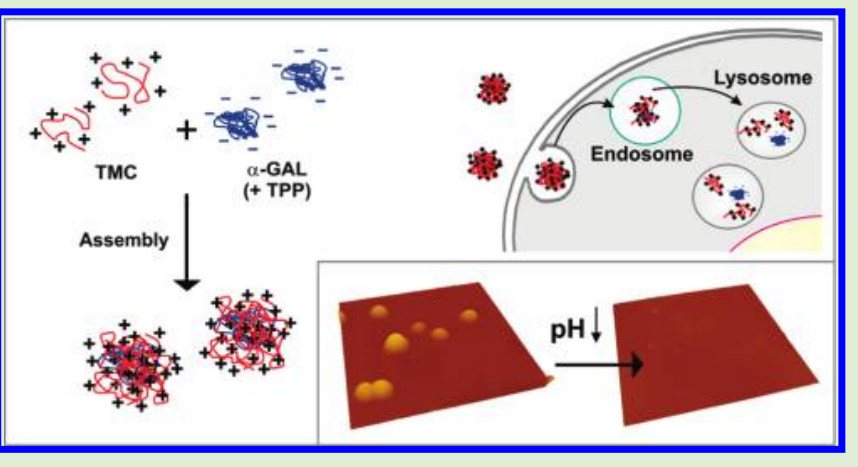
protein loading efficiency close to $65 \%$. These polyelectrolyte nanoparticles were stable and active under physiological conditions and able to release the enzyme at acidic $\mathrm{pH}$, as demonstrated by in situ atomic force microscopy (AFM). These nanoparticles were further functionalized with Atto $647 \mathrm{~N}$ for single-particle characterization and tracking their cellular uptake and fate using highresolution fluorescence microscopy. In contrast with their precursor, TMC, PECs were efficiently internalized by human endothelial cells and mostly accumulated in lysosomal compartments. The superior physicochemical characteristics of the TMC/ $\alpha$-GAL PECs together with their excellent cellular uptake properties indicate their enormous potential as advanced protein delivery systems for the treatment of lysosomal storage diseases.

\section{INTRODUCTION}

Targeting and drug delivery to specific cellular types and subcellular compartments is nowadays one of the major aims in the therapeutic field. In particular, the need of lysosomal targeting and delivery is mainly determined by various unresolved issues with the enzyme therapy of lysosomal storage diseases (LSDs), which are associated with the deficiency of certain lysosomal enzymes. ${ }^{1}$ However, a special concern with regard to lysosome drug delivery systems deals with the design of carriers able to release the drug at the endolysosomal compartments. Importantly, the only established strategy for treating LSDs is the enzyme replacement therapy (ERT) with exogenously administered recombinant enzyme. ${ }^{2-5}$ Nevertheless, this approach is not completely effective because the enzyme may be cleared from the blood by the liver and the spleen.

Nanoparticle-based drug delivery systems composed of a carrier and a bioactive molecule have been used to improve the activity and delivery of drugs. ${ }^{6}$ When properly designed, they may provide longterm blood circulation while protecting sensitive biomolecules, such as enzymes, from protease degradation and the attack of the immune system in vivo. ${ }^{7,8}$ Among available systems, polyelectrolyte complexes (PECs) formed by self-assembly between the therapeutic biomacromolecule (protein or DNA) and natural or synthetic polyelectrolytes have found many applications in the last few years because of their exclusive properties including biocompatibility and mild preparation conditions by means of simple synthesis procedures. ${ }^{9}$ PECs are association colloids, a class of colloidal systems in which oppositely charged molecules reversibly associate into multimolecular particles with a well-defined subcellular size and structure. ${ }^{10}$ This approach avoids the use of chemical cross-linking agents, thereby reducing the possible toxicity and other undesirable effects of the reagents. ${ }^{11}$

Additionally, the combination of this PEC strategy with a phenomenon like gelation, gives a more stable system and a 
higher degree of control of the structural properties of the nanoparticles. ${ }^{12}$ The particular case of ionotropic gelation, in which polyions are used as cross-linkers, occurs under gentle conditions compared with chemical cross-linking, allowing for a harmless entrapment of labile compounds, such as proteins. ${ }^{13}$ Besides, the formed physical hydrogels are, in general, mechanically weak, and specific changes in the external environment (e.g., ionic strength, $\mathrm{pH}$, temperature) may promote the disruption of the network, releasing its components.

Natural polysaccharides have drawn special attention as promising vectors in the field of drug delivery because they have various resources in nature and possess a large number of reactive groups to make their properties tunable, and many of them are biocompatible and easily degradable in the human body. ${ }^{14}$ Among them, chitosan nanoparticles have been used as carriers in protein and gene delivery for a number of different applications. ${ }^{9,15-18}$ Its outstanding characteristics such as the previously mentioned nontoxicity, biocompatibility, and biodegradability, together with its low cost, make chitosan one of the most widely used biopolymers in biomedical applications. ${ }^{19}$ Chitosan and its derivatives are cationic polymers (cationic polyelectrolytes) that can interact and form colloidal complexes with negatively charged biomacromolecules (DNA, proteins, polysaccharides) for nanoencapsulation purposes. ${ }^{20}$ Unfortunately, its poor aqueous solubility and loss of penetration-enhancing activity above $\mathrm{pH} 6$ have hampered its use under physiological conditions. ${ }^{21}$ Alternative approaches including quaternization of the amine groups of the chitosan molecule have been implemented to circumvent this drawback. ${ }^{22,23}$ Quaternized chitosan with the simplest alkyl group, trimethyl chitosan (TMC), has been used to complex and condense siRNA or DNA for gene delivery purposes $^{24-27}$ and insulin for oral and nasal delivery. ${ }^{20,22,28}$ However, its use for complexation and nanoencapsulation of other proteins of therapeutic interest, like lysosomal enzymes, remains underexplored.

$\alpha$-Galactosidase A ( $\alpha$-Gal A or $\alpha$-GAL) is a lysosomal enzyme responsible for the degradation of globotriaocylceramide (Gb3) and other neutral glycosphingolipids. ${ }^{29}$ Its deficiency leads to the Fabry disease and results in the lysosomal accumulation of Gb3 within various tissues and cells, in particular, the vascular endothelium. ${ }^{5,29}$ To date, the only strategy to treat this disease has consisted in ERT with exogenously administered $\alpha$-GAL. ${ }^{2-5}$ A very recent study reports the use of targeted model polystyrene nanocarriers to enhance the endothelial delivery of $\alpha$-GAL via specific interactions with ICAM- 1 molecules on the membrane of the endothelial cells. ${ }^{30}$

In this work, we describe for the first time the development of functional TMC-based PEC nanocarriers with the lysosomal enzyme $\alpha$-GAL, prepared by self-assembly via simple aqueous solution mixing and ionotropic gelation. We characterize their physicochemical properties, stability against time and temperature, behavior against the variation of the medium $\mathrm{pH}$, as well as intracellular trafficking and fate in human endothelial cells. Our data provide evidence that these $\alpha$-GAL nanocarriers are stable and active under physiological conditions and may facilitate acidic $\mathrm{pH}$-triggered release of the enzyme. Furthermore, they are internalized by endothelial cells and destined to lysosomal compartments, thus, representing valuable and promising therapeutic agents for Fabry disease, and may be extended to other lysosomal storage disorders.

\section{MATERIALS AND METHODS}

Synthesis of $\mathrm{N}$-Trimethyl Chitosan. Chitosan middle-viscous (CS) was purchased from Fluka. Its degree of deacetylation was determined to be $\sim 87 \%$ by ${ }^{1} \mathrm{H}$ NMR characterization. TMC was prepared following a two-step procedure described in the literature. ${ }^{31}$ The water-soluble product obtained was dissolved in water and freezedried (freeze-dryer ALPHA 1-4 LD, Christ). The presence of ternary and quaternary amines in the TMC obtained was verified by detection of the characteristic peaks of the di- and trimethyl amines in ${ }^{1} \mathrm{H}$ nuclear magnetic resonance $\left({ }^{1} \mathrm{H}\right.$ NMR) (data not shown). Around $28 \%$ degree of primary amines was obtained, calculated from the ${ }^{1} \mathrm{H}$ NMR spectrum (free amines). The molecular weight of the TMC was estimated via gel permeation chromatography (GPC) ${ }^{32}$ using Ultrahydrogel 250 and 500 columns and a Waters 24/4 IR detector in $0.5 \mathrm{M}$ acetate buffer $\mathrm{pH} 3$. Dextran standards were employed for calibration.

$\mathrm{CS}$ and TMC were characterized by $\mathrm{pH}$-potentiometric titration to obtain the degree of acetylation of CS and to evaluate the difference in buffer capacity of both polysaccharides. For this, $8 \mathrm{mg}$ of the polysaccharide were dissolved in $0.4 \mathrm{~mL}$ of $0.3 \mathrm{M}$ hydrochloric acid $(\mathrm{HCl})$ solution. A solution $0.06 \mathrm{M} \mathrm{NaOH}$ was then used for titration while the $\mathrm{pH}$ of the solution was monitored with a calibrated $\mathrm{pH}$-sensitive glass electrode. The procedure results in a titration curve with two inflection points: the first one corresponds to the excess of $\mathrm{HCl}$, and the second one corresponds to the protonated CS. The difference between the two inflection points yields the moles of $\mathrm{H}^{+}$required for the protonation of the free (deacetylated) amino groups and is related to the buffer capacity of the polymer.

Polyelectrolyte Complexes Formation. Recombinant $\alpha$-GAL (obtained by transient gene expression in the HEK 293F cell line and purified by affinity chromatography) $)^{33}$ was kindly supplied by Dr. J. L. Corchero and Prof. A. Villaverde from the Institute for Biotechnology and Biomedicine, Autonomous University of Barcelona (IBB, UAB).

The PECs between $\alpha$-GAL and TMC were prepared by the addition of a solution of TMC (in $10 \mathrm{mM}$ HEPES buffer $\mathrm{pH} 7.4$ to 7.5 ) at various concentrations (24.5 to $100 \mu \mathrm{g} \mathrm{mL}^{-1}$ ) to a solution of $\alpha$-GAL $100 \mu \mathrm{g} \mathrm{mL}^{-1}$ (in $10 \mathrm{mM}$ HEPES buffer $\mathrm{pH}$ 7.4) in a volume ratio $70: 30$, followed by vortex mixing for $5 \mathrm{~s}$ and incubation at room temperature for at least $60 \mathrm{~min}$. When penta-sodium triphosphate (TPP, Fluka) was used to induce ionotropic gelation, it was first dissolved in the protein solution to a concentration of $23 \mu \mathrm{g} \mathrm{mL}^{-1}$, and the TMC solution was added afterward for PECs formation. Whenever indicated, a separation step from uncomplexed $\alpha$-GAL and TMC was performed by centrifugation using Nanosep Centrifugal Devices of 300K MWCO (Pall Corporation) at relative centrifugal force (RCF) of $2000 \mathrm{~g}$ for $7 \mathrm{~min}$.

Size, Zeta Potential, and Morphology Characterization. The average size $(D)$, polydispersity index $(\mathrm{PDI})$, and $\zeta$-potential values for the PEC suspensions were determined by dynamic light scattering (DLS) with a Zetasizer Nano ZS (Malvern Instruments) equipped with a He-Ne laser $(\lambda=633 \mathrm{~nm})$ as the incident beam using folded capillary cells. The PDI describes the width of the particle size distribution, and for a single-size population following a Gaussian distribution, it is defined as PDI $=(\sigma / D)^{2}$, where $\sigma$ is the standard deviation of the distribution.

The TMC/ $\alpha$-GAL PECs were visualized by atomic force microscopy (AFM) (Dimension 3100, Nanoscope IV controller, Veeco, Digital Instruments, Santa Barbara, CA). A drop of the suspension sample was placed on top of freshly cleaved highly ordered pyrolytic graphite (HOPG) and left for $30 \mathrm{~min}$. Then, the solution was removed and replaced with $10 \mathrm{mM}$ HEPES buffer $\mathrm{pH} 7.4$ (with no drying step in between) for imaging under a controlled liquid environment in tapping mode. V-shaped silicon nitride cantilevers with a pyramidal tip (nominal spring constant $0.32 \mathrm{~N} \mathrm{~m}^{-1}$, nominal tip radius $20 \mathrm{~nm}$ ) were used for imaging. 
Loading Efficiency. To determine the loading efficiency (LE) of PECs, we separated the uncomplexed TMC and $\alpha$-GAL from the prepared PECs using Nanosep Centrifugal Devices of 300K MWCO (Pall Corporation) at RCF $=2000 \mathrm{~g}$ for $7 \mathrm{~min}$. The amount of $\alpha$-GAL in the original PECs suspension (total amount of $\alpha$-GAL) as well as the free $\alpha$-GAL in the filtered solution (filtrate) was determined with the standard bicinchoninic acid (BCA) assay (Micro BCA protein assay kit, Thermo Scientific). Standard solutions of $\alpha$-GAL of different concentrations were used as calibration. The LE was calculated from

$$
\mathrm{LE}=\frac{\text { total amount of } \alpha-\mathrm{GAL}-\text { free } \alpha-\mathrm{GAL}}{\text { total amount of } \alpha-\mathrm{GAL}} \times 100
$$

Enzymatic Activity. The enzymatic activity of $\alpha$-GAL was determined with a fluorometric assay. In brief, $25 \mu \mathrm{L}$ of the sample ( $\alpha$-GAL or PEC, diluted in $10 \mathrm{mM}$ acetate buffer $\mathrm{pH} 4.5$ to 1:500, 1:1000, 1:2000, and $1: 4000$ ) were incubated with $100 \mu \mathrm{L}$ of $2.46 \mathrm{mM}$ 4-methylumbelliferyl- $\alpha$-D-galactopiranoside solution in $10 \mathrm{mM}$ acetate buffer $\mathrm{pH} 4.5$, in a bath at $37{ }^{\circ} \mathrm{C}$ with constant shaking during $1 \mathrm{~h}$. The reaction was stopped by the addition of $1.25 \mathrm{~mL}$ of $100 \mathrm{mM}$ glycine buffer $\mathrm{pH}$ 10.4. A spectrofluorophotometer (RF-1050 Shimadzu) was used to read the fluorescence of the samples $\left(\lambda_{\mathrm{ex}}=365 \mathrm{~nm}, \lambda_{\mathrm{em}}=450 \mathrm{~nm}\right)$, corresponding to the 4-methylumbelliferone (4-MU) produced during the reaction. A calibration curve was obtained with 4-MU standard solutions (from 0 to $250 \mathrm{ng} \mathrm{mL}^{-1}$ ) in $100 \mathrm{mM}$ glycine buffer $\mathrm{pH} 10.4$. The enzymatic activity was calculated as $\mu \mathrm{mol}_{(4-\mathrm{MU})} \mathrm{h}^{-1}$, and the specific enzymatic activity (activity of the enzyme per milligram of the total protein mass) was calculated as $\mu \mathrm{mol}_{(4-\mathrm{MU})} \mathrm{mg}_{(\alpha-\mathrm{GAL})}{ }^{-1} \mathrm{~h}^{-1}$.

Preparation of Fluorescently Labeled PECs. TMC was conjugated to the fluorescent dye Atto 647N NHS ester (Fluka). Atto 647N NHS was first dissolved in a small amount of dimethyl sulfoxide (DMSO) and then diluted with $10 \mathrm{mM}$ HEPES buffer $\mathrm{pH}$ 7.4. This solution was added to a TMC solution (in $10 \mathrm{mM}$ HEPES $\mathrm{pH}$ 7.4) in an approximate molar ratio of $3: 1$ and left to react for $1 \mathrm{~h}$ at room temperature under magnetic stirring. Atto $647 \mathrm{~N}$-conjugated TMC (Atto647N-TMC) was separated from the free dye using Zeba desalt spin columns (Thermo Scientific). To increase the amount of covalently attached Atto $647 \mathrm{~N}$ into TMC, we performed a second conjugation step with freshly prepared Atto 647N NHS solution for another hour. Afterward, the fluorescently labeled TMC was purified with Zeba desalt spin columns as described above. The Atto647N-TMC solution was freeze-dried (freeze-dryer Vis-Tris Freezemobile 25L). The amount of conjugated dye was estimated to be $0.32 \mathrm{~mol}$ dye per mol TMC via UV-visible spectrometry (NanoDrop Spectrophotometer ND-1000). The fluorescently labeled PECs were prepared by mixing a solution of unlabeled TMC and Atto647N-TMC (in $10 \mathrm{mM}$ HEPES buffer $\mathrm{pH} 7.4$ to 7.5 ) in a volume ratio $70: 30$ with the $\alpha$-GAL/TPP solution in the same buffer, as previously described.

Single-Molecule Fluorescence Microscopy. Atto647N-labeled PECs in $10 \mathrm{mM}$ HEPES $\mathrm{pH} 7.4$ were adsorbed to a glass coverslip for visualization by wide-field microscopy. Imaging was performed on a home-built wide-field epifluorescence setup arranged around an Olympus IX70 inverted microscope equipped with a $37^{\circ} \mathrm{C}$ heated chamber. Samples were observed while illuminated for $5 \mathrm{~ms}$ at $630 \mathrm{~nm}$ by a $\mathrm{He}-\mathrm{Ne}$ laser. The optical configuration adopted consists of an illumination area of $27 \times 27$ $\mu \mathrm{m}^{2}$ with an excitation intensity of $1.35 \mathrm{~kW} \mathrm{~cm}{ }^{-2}$. Fluorescence was collected with a 1.45 N.A. oil immersion objective (PLAPON 60XO TIRFM, Olympus) and guided into an intensified CCD camera (IPentamax, Princeton Instruments) through appropriate optics.

Cell Culture. Human microvascular endothelial cell line, CDC/EU. HMEC-1 (HMEC-1), was obtained from Centers for Disease Control and Prevention/National Center for Infectious Diseases (CDC-NIDR). HMEC-1 cells were cultured in MCDB 131 (Invitrogen) with 50 units $\mathrm{mL}^{-1}$ penicillin, $50 \mu \mathrm{g} \mathrm{mL}^{-1}$ streptomycin, and $10 \mathrm{mM}$ L-glutamine and supplemented with $10 \%$ fetal bovine serum (FBS) in a humidified atmosphere with
$5 \% \mathrm{CO}_{2}$ at $37^{\circ} \mathrm{C}$. All of the media, sera, and antibiotics were purchased from Invitrogen.

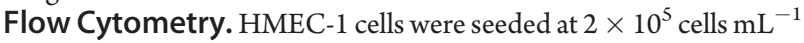
$36-48 \mathrm{~h}$ prior to experiment. Cells were detached using trypsin, washed with Dulbecco's phosphate-buffered saline (DPBS), and resuspended in MCDB 131 supplemented with $10 \mathrm{mM}$ L-glutamine without FBS. Approximately $10^{5}$ cells were incubated with $15 \mu \mathrm{g} \mathrm{mL}{ }^{-1}$ Atto647PECs for $2 \mathrm{~h}$ at 16 or $37^{\circ} \mathrm{C}$. Cells were subsequently washed twice with DPBS, resuspended in $300 \mu \mathrm{L}$ of DPBS, and subjected to fluorescenceactivated cell sorting (FACS) analysis. Data acquisition and analysis was performed using a Gallios flow cytometer (Beckman Coulter). We evaluated 10000 viable cells in each experiment, and the results are the mean of three independent measurements.

Confocal Laser Scanning Microscopy (CLSM). HMEC-1 cells were seeded onto Fluorodish culture plates (World Precision Instruments, Sarasota, FL) at a density of $2 \times 10^{5}$ cells plate $^{-1}$ and allowed to grow for 36-48 h. Fluorescently labeled PECs were incubated with the cells for 0.5 to $3 \mathrm{~h}$ at $37^{\circ} \mathrm{C}$ in serum-free MCDB 131 supplemented with $10 \mathrm{mM}$ L-glutamine. Subsequently, cells were washed three times with serum-free MCDB 131 and incubated at $37{ }^{\circ} \mathrm{C}$ for $10 \mathrm{~min}$ with Lysotracker Green DND-26 (50 nM, Molecular probes, Eugene, Oregon) to label the endosomal/lysosomal compartments. The nuclei in live cells were stained with Hoechst 33342 dye (Sigma). Cells were examined under an inverted Leica SP5 scanning confocal microscope $(60 \times 1.42$ NA oil immersion objective $)$ fitted with a CCD camera. Data acquisition and analysis was performed with LAS-AF software and ImageJ.

\section{RESULTS AND DISCUSSION}

TMC Synthesis and Characterization. Chitosan (CS) is a weak base, which requires a certain number of protons to transform the glucosamine units into the positively charged water-soluble form. The cationic form of chitosan can interact and form complexes with proteins that bear a negative charge. This occurs only at a range of $\mathrm{pH}$ values in which the amino groups of the polysaccharide are protonated, and, naturally, the $\mathrm{pH}$ of the medium is higher than the isoelectric point ( $\mathrm{pI}$ ) of the protein. $\alpha$-GAL is a homodimeric glycoprotein, and it is markedly negatively charged. With 47 carboxylate groups and only 36 basic residues in the 398 residues in the molecule, the overall charge per monomer is expected to be -11 at neutral $\mathrm{pH}^{29}$ and its $\mathrm{pI}$ is $\sim 5.7$. However, the degree of protonation of chitosan around neutral $\mathrm{pH}$ is not sufficient to render it soluble and, in turn, associate with the protein to form stable complexes $\left(\mathrm{p} K_{\mathrm{a}}\right.$ of chitosan is around 5.5 to 6.5 ).

To have a suitable polyelectrolyte able to form complexes with $\alpha$-GAL, we prepared partially quaternized chitosan with the simplest alkyl group (methyl) (TMC), with ca. 50\% of quaternary amines, as determined by ${ }^{1} \mathrm{H}$ NMR. We also observed 22 and $31 \%$ of $\mathrm{O}$-methylation for C-3 and C-6, respectively. ${ }^{23}$ The molecular weight of the TMC was estimated to be $202000 \mathrm{~g}$ $\mathrm{mol}^{-1}$ with a polydispersity of 2.6, using GPC. The product had a $\mathrm{p} K_{\mathrm{a}}$ value of 6.1 and was fully soluble in both water and HEPES buffer at $\mathrm{pH} 7.4$ to 7.5 .

The $\mathrm{pH}$-potentiometric titration curves of CS and TMC acidified solutions with a strong base $(\mathrm{NaOH})$ are compared in Figure 1. These curves exhibit two inflection points. The first one is due to the neutralization of excess $\mathrm{HCl}$, whereas the second one is ascribed to the neutralization of the protonated amine groups. The difference in volume of $\mathrm{NaOH}$ between the two inflection points is related to the buffer capacity of the polymer. It is evident from the curves that TMC acid solution requires a 
higher amount of $\mathrm{NaOH}$ to neutralize the free acid because there are fewer free amine groups to be protonated because of quarternization and many fewer to neutralize the protonated amino groups $\left(\Delta V_{\mathrm{CS}}=370 \mu \mathrm{L}\right.$ and $\left.\Delta V_{\mathrm{TMC}}=75 \mu \mathrm{L}\right)$. For TMC, a smaller percentage of the amines is now protonable (28\% for TMC compared with $87 \%$ for CS), and the macromolecule's overall charge is positive independently of the $\mathrm{pH}$ of the medium. Together, these data indicate that the buffer capacity of chitosan is strongly diminished after partial quaternization.

TMC/ $\alpha-G A L$ Association Polyelectrolyte Complexes. The ability of the synthesized TMC to complex $\alpha-G A L$ and form PECs was evaluated. For this, the TMC $/ \alpha$-GAL mass ratio was varied by the addition of TMC solution at different concentrations to the solution of $\alpha-\mathrm{GAL}$ in a volume ratio of 70:30. The formation of relatively stable complexes between TMC and $\alpha$ GAL was observed over the $\mathrm{pH}$ range from 7.3 to 8.0 by monitoring the average diameter and $\zeta$-potential of the suspension by DLS. At $\mathrm{pH}$ values of 4.5 to 5.5 , which are close to the isoelectric point of the protein ( $\mathrm{pI} \sim 5.7$ ), no complex formation was detected. In the $\mathrm{pH}$ range 7.3 to 8.0 , the electrostatic interaction between the negatively charged $\alpha-G A L$ and the positively charged TMC led to complexes of average diameter between 50 to $90 \mathrm{~nm}$ and PDI between 0.2 and 0.4, depending on the mass ratio of the two components (see Table 1 ). An increase in the TMC/ $\alpha$-GAL mass ratio resulted in a decrease in the average size of the PECs, although a broadening in the size distribution (higher PDI) was evident. All suspensions showed a positive $\zeta$-potential in the range between 10 and $23 \mathrm{mV}$. After storage at $4{ }^{\circ} \mathrm{C}$ for 1 day, these PECs showed a slight increase in size and PDI, whereas the $\zeta$-potential values reached a relatively constant positive magnitude ( 24 to $29 \mathrm{mV}$ ) (see Table 1 ). However, the size distribution for these complexes was still considerably broad (PDI $\geq 0.2$ ).

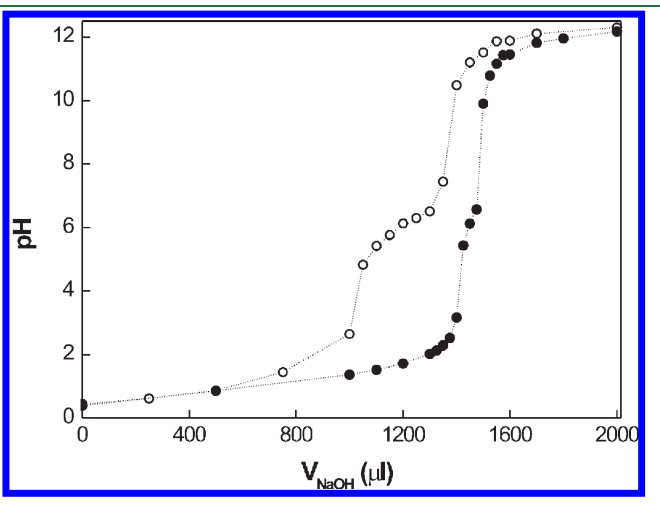

Figure 1. $\mathrm{pH}-$ Potentiometric titration curves of an acidified solution of chitosan $(\bigcirc)$ or TMC $(\bullet)$ with $\mathrm{NaOH} 0.06 \mathrm{M}$.
As stated by many reports, the physicochemical properties such as particle size, shape, surface charge, and composition have been shown to play a key role in the blood circulation, cellular uptake, and subsequent cellular routing of polymeric nanoparticles. ${ }^{34-37}$ An empirical hydrodynamic diameter for efficient cellular uptake and systematic delivery of nanoparticulate material has been established to be $<200 \mathrm{~nm} .^{36,38}$ Thus, an accurate control of the size distribution (average size and polydispersity) of the TMC/ $\alpha$-GAL PECs might be crucial for their activity in vivo. To enhance the stability and size homogeneity of the TMC/ $\alpha$-GAL PECs, we introduced the polyanion penta-sodium triphosphate (TPP) to the system to induce some extent of ionic cross-linking because it can interact with amines of different TMC molecules to give reversible and $\mathrm{pH}$-dependent ionically cross-linked hydrogels.

The amount of TPP was chosen to have a variation of TMC/ TPP mass ratio between 2.5 and 10.3, whereas the TMC amount was changed. Initially, TPP was premixed with $\alpha$-GAL, both negatively charged in HEPES buffer at $\mathrm{pH}$ 7.5. Subsequently, the TMC solution was added to the previous solution and stirred. For a fixed amount of protein and TPP, the mass of TMC was varied. In Table 2 , the DLS average size, PDI, and $\zeta$-potential for the PECs prepared with TPP for various TMC/ $\alpha-G A L$ mass ratios are displayed. The incorporation of TPP in the system led to an increase in the average size of the PECs, although the average particle diameter was always $<200 \mathrm{~nm}$. Importantly, very narrow distributions were attained $(\mathrm{PDI} \leq 0.2)$ with these PECs. Although their $\zeta$-potential values were significantly smaller than those with formulations lacking TPP right after preparation (60 min), they reached constant $\zeta$-potential values in $\sim 2 \mathrm{~h}$. It is noteworthy that the $\zeta$-potential approached $20 \mathrm{mV}$ for the formulations with $\mathrm{TMC} / \alpha-\mathrm{GAL}$ mass ratio $\geq 0.82$. As shown in Table 2 and Figure 2, the average size decreased with the increment in the TMC/ $\alpha$-GAL ratio (and, accordingly, the increase in the TMC/TPP ratio), whereas the PDI showed the opposite trend. These observations are in accordance with some reported studies for insulin- or DNA-loaded CS/TPP nano- and microparticles $^{9,39,40}$ and insulin-loaded TMC/TPP nanoparticles. ${ }^{40,41}$ All four ratios tested present a monomodal narrow size distribution (Figure 2).

Following these results, selection of the best PECs was based on the following criteria: minimum amount of TMC and TPP per PEC, which give constant $\zeta$-potential value, high stability, narrow size distribution, and average particle size $<200 \mathrm{~nm}$. Because the $\zeta$-potential value for PECs with TMC/ $\alpha$-GAL mass ratio of 0.57 has still not reached the constant value of $20 \mathrm{mV}$, PECs with a TMC/ $\alpha-G A L$ mass ratio of 0.82 and TMC/TPP mass ratio of 3.6 (named PEC0.82 from here on) were chosen for further studies. Furthermore, a shift of the size distribution

\section{Table 1. DLS Characterization of TMC/ $\alpha-$ GAL PECs ${ }^{a}$}

\begin{tabular}{|c|c|c|c|c|c|c|}
\hline \multirow[t]{2}{*}{ TMC/ $\alpha$-GAL mass ratio } & \multicolumn{3}{|c|}{$t_{0} \approx 60 \mathrm{~min}$} & \multicolumn{3}{|c|}{$t_{1} \approx 24 \mathrm{hs}$} \\
\hline & $D(\mathrm{~nm})$ & PDI & $\zeta$ potential $(\mathrm{mV})$ & $D(\mathrm{~nm})$ & PDI & $\zeta$ potential $(\mathrm{mV})$ \\
\hline$\alpha-G A L$ & & & $-36.6 \pm 6.7$ & & & \\
\hline 0.82 & 87.0 & 0.191 & $18.4 \pm 8.8$ & 92.1 & 0.216 & $24.1 \pm 6.0$ \\
\hline 1.17 & 72.6 & 0.245 & $22.9 \pm 5.6$ & 82.3 & 0.345 & $28.9 \pm 5.2$ \\
\hline 2.33 & 53.9 & 0.396 & $10.5 \pm 10.0$ & 70.4 & 0.416 & $27.2 \pm 5.7$ \\
\hline TMC & & & $17.7 \pm 23.0$ & & & \\
\hline
\end{tabular}

${ }^{a}$ Average diameter $(D)$, polydispersity index (PDI), and $\zeta$ potential obtained at $25^{\circ} \mathrm{C}$ for TMC/ $\alpha$-GAL PECs in $10 \mathrm{mM} \mathrm{HEPES} \mathrm{pH} 7.3$ for TMC/ $\alpha$ GAL mass ratios from 0.82 to 2.33 , as prepared $\left(t_{0}\right)$ and after $24 \mathrm{~h}\left(t_{1}\right)$. 
Table 2. Loading Efficiency (LE) and DLS Characterization of TMC/ $\alpha$-GAL PECs with TPP upon Time ${ }^{a}$

\begin{tabular}{|c|c|c|c|c|c|c|c|c|}
\hline \multirow{2}{*}{$\begin{array}{l}\mathrm{TMC} / \alpha-\mathrm{GAL} \\
\text { mass ratio }\end{array}$} & \multirow{2}{*}{$\begin{array}{l}\text { TMC/TPP } \\
\text { mass ratio }\end{array}$} & \multicolumn{3}{|c|}{$t_{0} \approx 60 \mathrm{~min}$} & \multicolumn{3}{|c|}{$t_{1} \approx 4$ days } & \multirow[b]{2}{*}{$\operatorname{LE}(\%)^{b}$} \\
\hline & & $D(\mathrm{~nm})$ & PDI & $\zeta$ potential $(\mathrm{mV})$ & $D(\mathrm{~nm})$ & PDI & $\zeta$ potential $(\mathrm{mV})$ & \\
\hline 0.57 & 2.5 & 156.0 & 0.063 & $6.98 \pm 7.4$ & 163.5 & 0.081 & $15.9 \pm 5.7$ & 65 \\
\hline $0.82^{c}$ & 3.6 & 141.5 & 0.156 & $8.45 \pm 6.6$ & 141.2 & 0.095 & $20.3 \pm 4.2$ & 63 \\
\hline 1.17 & 5.1 & 129.0 & 0.151 & $11.4 \pm 8.3$ & 129.2 & 0.130 & $20.0 \pm 7.3$ & 63 \\
\hline 2.33 & 10.3 & 86.3 & 0.232 & $4.50 \pm 5.2$ & 111.0 & 0.290 & $24.0 \pm 6.7$ & 56 \\
\hline
\end{tabular}

${ }^{a}$ Average diameter $(D)$, polydispersity index (PDI), and $\zeta$ potential obtained by DLS at $25^{\circ} \mathrm{C}$ for TMC/ $\alpha$-GAL PECs in $10 \mathrm{mM} \mathrm{HEPES} \mathrm{pH} 7.5$, for TMC/ $\alpha$-GAL mass ratios from 0.57 to 2.33 , with TPP (TMC/TPP mass ratio from 2.5 to 10.3 ), as prepared $\left(t_{0}\right)$, and after 4 days at $4{ }^{\circ} \mathrm{C}\left(t_{1}\right)$. The standard deviation of the average diameter $(D)$ and $\zeta$-potential values were $11 \mathrm{~nm}$ and $1.4 \mathrm{mV}$, respectively. ${ }^{b}$ Standard deviation in the LE is $6 \%$. ${ }^{c}$ PEC0.82

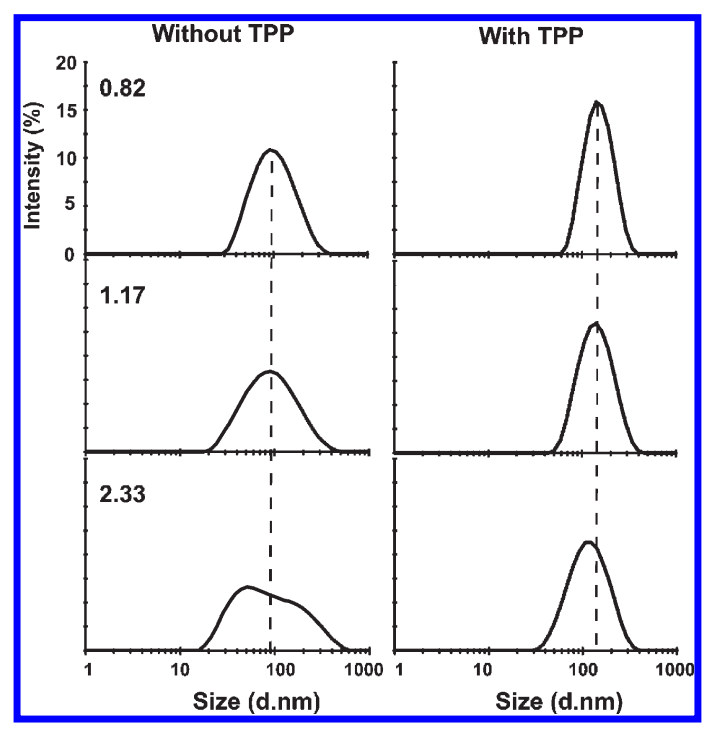

Figure 2. DLS size distribution at $25{ }^{\circ} \mathrm{C}$ for TMC/ $\alpha$-GAL PECs for different TMC/ $\alpha$-GAL mass ratios $(0.82,1.17,2.33)$ without and with the addition of the polyanion TPP (in TMC/TPP mass ratios as in Table 2). The standard deviation of the average diameter $(D)$ for the samples with TPP was $11 \mathrm{~nm}$.

curve toward higher size values can be observed for the PEC with a TMC/ $\alpha$-GAL mass ratio of 0.57 , which results in a higher fraction of PECs with diameters $\geq 200 \mathrm{~nm}$.

To assess the morphology of TMC/ $\alpha$-GAL PECs, we used AFM under liquid conditions. A topographical image of the PECs (TMC/ $\alpha$-GAL mass ratio of 0.82 and TMC/TPP mass ratio of 3.6) adsorbed onto HOPG is shown in Figure 3. Clearly, the TMC/ $\alpha$-GAL PECs are nanoparticles that appear spherical in shape and homogeneous, and no aggregation is observed (Figure 3).

Loading Efficiency and Protein Functionality after Entrapment into PECs. To determine the protein LE of the PECs, we separated them from uncomplexed $\alpha-G A L$ and TMC through centrifugal filtration. The LE was calculated from eq 1 (see Materials and Methods section) and ranged from 56 to $65 \%$ for TMC/ $\alpha$-GAL PECs with different mass ratios (Table 2 ). These data indicate that the LE is barely affected by the increase in the relative $\alpha$-GAL concentration in the formulations for TMC/ $\alpha$ GAL mass ratios between 1.17 and 0.57 . The original solution of $\alpha$-GAL was also filtered to examine the extent of $\alpha$-GAL adsorption onto the filter membrane. The total enzyme amount was recovered in the filtrate, indicating that all protein in the

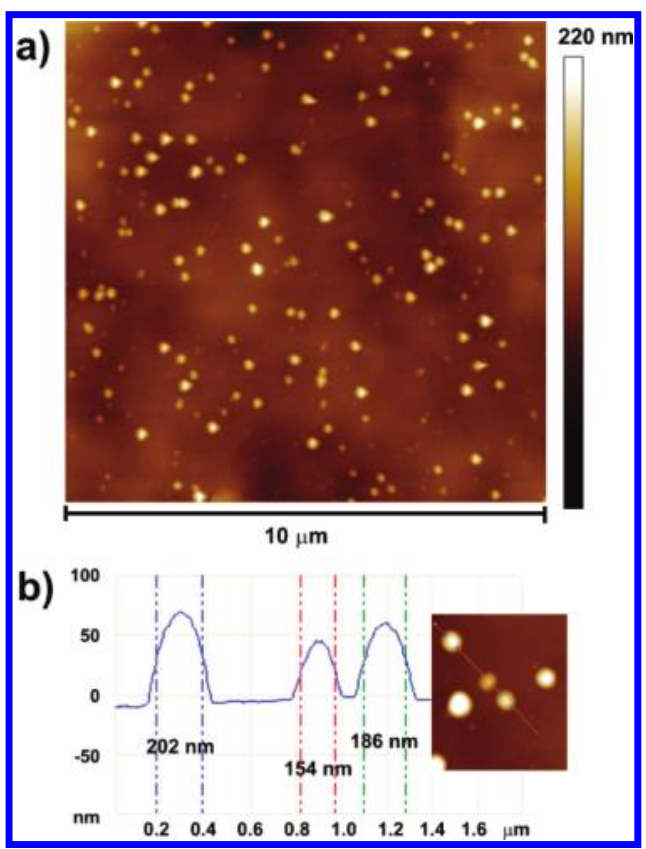

Figure 3. (a) AFM image (height, tapping mode) of a TMC/ $\alpha$-GAL PEC in a mass ratio of 0.82 with TPP (TMC/TPP mass ratio: 3.6) on an HOPG substrate in $10 \mathrm{mM}$ HEPES buffer $\mathrm{pH}$ 7.5. (b) Profile from the AFM topographic image. From DLS, $D=163.6 \mathrm{~nm}$ and PDI $=0.097$ for this sample.

retenate fraction of the PEC suspension corresponded to $\alpha$-GAL associated into PECs.

Furthermore, because protein function is dependent on a precise and fragile 3D structure that may be difficult to maintain when nanocarriers are used for protein delivery purposes, the effect of protein entrapment by TMC into the $\alpha$-GAL functionality was assessed. The specific enzymatic activity of the TMC/ $\alpha$ GAL PEC suspension after centrifugal filtration was measured. In comparison with the $\alpha$-GAL solution (without TMC), the PECs displayed $62 \%$ of the specific activity (Figure $4 a$ ). These measurements were taken at $\mathrm{pH} 4.5$, the optimum $\mathrm{pH}$ of activity of $\alpha$ GAL. These results might suggest that at $\mathrm{pH} 4.5$ the complexed enzyme is not completely masked by the TMC and remains accessible to its substrate. Alternatively, the enzyme might have been dissociated from the PECs and released to the medium.

Time and Temperature Stability of the TMC/ $\alpha-G A L$ PECs. To evaluate their stability, we measured the average size and PDI of PECs prepared with the various TMC/ $\alpha$-GAL ratios and with 


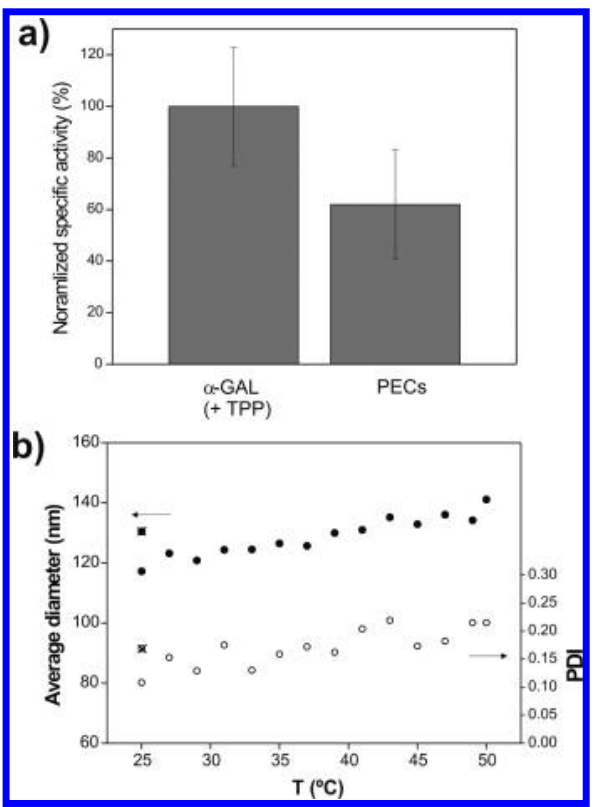

Figure 4. (a) Specific enzymatic activity of TMC/ $\alpha$-GAL PEC0.82 normalized to the specific activity of $\alpha$-GAL (+TPP, without TMC). Activity measurements were taken $5 \mathrm{~h}$ after PEC preparation. (b) Variation of the average size (O) and PDI (O) of a PEC 0.82 with temperature. Increments of $2{ }^{\circ} \mathrm{C}$ were applied, with 10 min stabilization time at each temperature before the size distribution was measured. The crossed symbols correspond to the measurement at $25{ }^{\circ} \mathrm{C}$ after the heating cycle. The standard deviation of the average diameter $(D)$ and $\zeta$ potential values were determined to be $11 \mathrm{~nm}$ and $1.4 \mathrm{mV}$, respectively.

the corresponding amount of TPP, as in Table 2, upon preparation and after 4 days stored at $4{ }^{\circ} \mathrm{C}$. As shown in Table 2 , the average size and PDI of the TMC/ $\alpha$-GAL PECs did not change significantly over time, and no evidence of aggregation or flocculation of the nanoparticles could be observed for any of the mass ratios tested. As previously mentioned, we observed that $2 \mathrm{~h}$ after preparation the $\xi$-potential of the PECs with TMC/ $\alpha$-GAL mass ratios of 0.82 and higher arrived to a constant value. This might be ascribed to a surface charge rearrangement during the first hours after preparation because of diffusion of ions in and outside the PECs. To assess longer times, we left a suspension of TMC/ $\alpha$-GAL PEC0.82 at $4{ }^{\circ} \mathrm{C}$, and the average size and PDI were tested after 25 days. No significant variations from the original values were found $(D=155.7 \mathrm{~nm}, \mathrm{PDI}=0.067, \zeta$ potential $=19.9 \pm 5.4 \mathrm{mV})$. It is clear that the surface charge leading to the $\zeta$-potential values herein obtained, that is, $\sim 20 \mathrm{mV}$, appears to be enough to provide electrostatic repulsion and prevent the particles from aggregating. We evaluated the reproducibility of the preparation method by measuring the size distribution and $\zeta$ potential of seven samples prepared under the same conditions, and a standard deviation of $11 \mathrm{~nm}$ and $1.4 \mathrm{mV}$ was obtained for the average diameter and $\zeta$-potential values, respectively.

The effect of the temperature on the TMC/ $\alpha-G A L$ PEC stability (average diameter, PDI) was evaluated in a range from 25 to $50{ }^{\circ} \mathrm{C}$. For this, a suspension of PEC 0.82 was placed in the DLS cell, and the temperature in the chamber was scanned with increments of $2{ }^{\circ} \mathrm{C}$ and $10 \mathrm{~min}$ stabilization time at each temperature. Afterward, the cell was left to cool to $25^{\circ} \mathrm{C}$, and the size distribution was again recorded. A plot of average particle size and PDI versus temperature is shown in Figure $4 \mathrm{~b}$. A modest increase in the average particle diameter (and PDI) was observed as a function of temperature, which is consistent with some extent of thermal expansion (reversible swelling) because after cooling back to $25{ }^{\circ} \mathrm{C}$ the size distribution is very close to the initial one (crossed symbols in Figure $4 \mathrm{~b}$ ). This result indicates that the colloidal PEC suspension is stable in the temperature range of $25-50{ }^{\circ} \mathrm{C}$ and that at a physiological temperature $\left(37^{\circ} \mathrm{C}\right.$ ) only a $7 \%$ increment in the average particle size is obtained. Similar results were obtained when the incubation time was $1 \mathrm{~h}$ at $37^{\circ} \mathrm{C}$ (data not shown). Moreover, size and PDI values always remained within a satisfactory range (average diameter $\leq 200 \mathrm{~nm}$ with PDI $\leq 0.20$ ).

pH-Triggered Protein Release. Colloidal complexes are most often trafficked rapidly from endosomes to lysosomes, which are highly acidic and rich in degrading enzyme such as $\alpha$ $\mathrm{GAL}$, the defective enzyme in the Fabry disease. The acid $\mathrm{pH}$ of lysosomes ( $\mathrm{pH} 4.5$ ) stabilizes the enzyme and confers optimum conditions for its activity. Hence, endosomal/lysosomal $\mathrm{pH}$ (between 5.5 and 4.5) can act as a trigger for the release of the protein from the PEC.

To analyze the effect of $\mathrm{pH}$ on the PEC structure and stability, we monitored the particle size distribution (average diameter and PDI) of a sample of PEC 0.82 while the $\mathrm{pH}$ was gradually dropped by the addition of small amounts of $\mathrm{HCl}$ solution. At $\mathrm{pH} 7.5$, the system had an average diameter of $155 \mathrm{~nm}$ with a PDI of 0.067. (See Figure 5a.) The particle average size and PDI remained unaltered until $\mathrm{pH} 6.8$ was reached (Figure 5b). Further $\mathrm{pH}$ decreases led to an increase in the average diameter and the loss of monomodal size distributions, with the consequent increase in PDI (Figure 5). At pH 5.1, the size distribution showed a mean value of $702.2 \mathrm{~nm}$, with a PDI of 0.439 (Figure 5a). The $\mathrm{pH}$ effect on the PEC structure is better noticed by plotting the PDI against $\mathrm{pH}$ because the average size does not provide information about modality of the distribution (monomodal, multimodal). As shown in Figure 5b, an inflection in the PDI- $\mathrm{pH}$ curve occurs around $\mathrm{pH}$ 6.7. These observations can be attributed to either aggregation of the PECs or their destabilization due to weakening of the attraction forces between the associated components. Because the $\zeta$-potential of the PECs is around $+20 \mathrm{mV}$, the $\mathrm{pH}$ decrease is not expected to induce aggregation because charge repulsion will not be strongly affected (e.g., the $\zeta$-potential of the suspension at $\mathrm{pH} 4.1$ is around $+29 \mathrm{mV})$. Even when the chitosan charge density is strongly dependent on $\mathrm{pH}, \mathrm{TMC}$ has much lower degree of $\mathrm{pH}$ dependency of positive charge density. However, the $\mathrm{pH}$ affects in a greater extent the protein charge density (as it approaches $\mathrm{pI}$ ). Because strong electrostatic interactions are the most predominant molecular forces that hold the PEC assembly, the $\mathrm{pH}$ drop may weaken the assembly and, as a consequence, release the protein.

To understand further the effect of $\mathrm{pH}$ on the TMC/ $\alpha-\mathrm{GAL}$ PEC structure, we performed an AFM inspection of the PECs adsorbed onto HOPG in situ while $\mathrm{pH}$ was decreased from 7.5 to 3.9. As shown in Figure 5b, the spherical nanoparticulate PECs are readily disassembled upon a $\mathrm{pH}$ drop from 7.5 to 3.9.

Cellular Uptake Studies of TMC/ $\alpha-$ GAL PECs. The major clinical manifestations of Fabry disease are thought to be caused by a progressive accumulation of Gb3 and other glycosphingolipids in vascular endothelial cells. ${ }^{2}$ These cells thus represent the target of choice for therapeutical intervention. To assess the uptake of TMC/ $\alpha$-GAL PECs into endothelial cells, we used HMEC-1, which is an immortalized human microvascular endothelial cell line that retains the morphologic, phenotypic, and functional characteristics of normal human microvascular endothelial cells. ${ }^{42}$ 

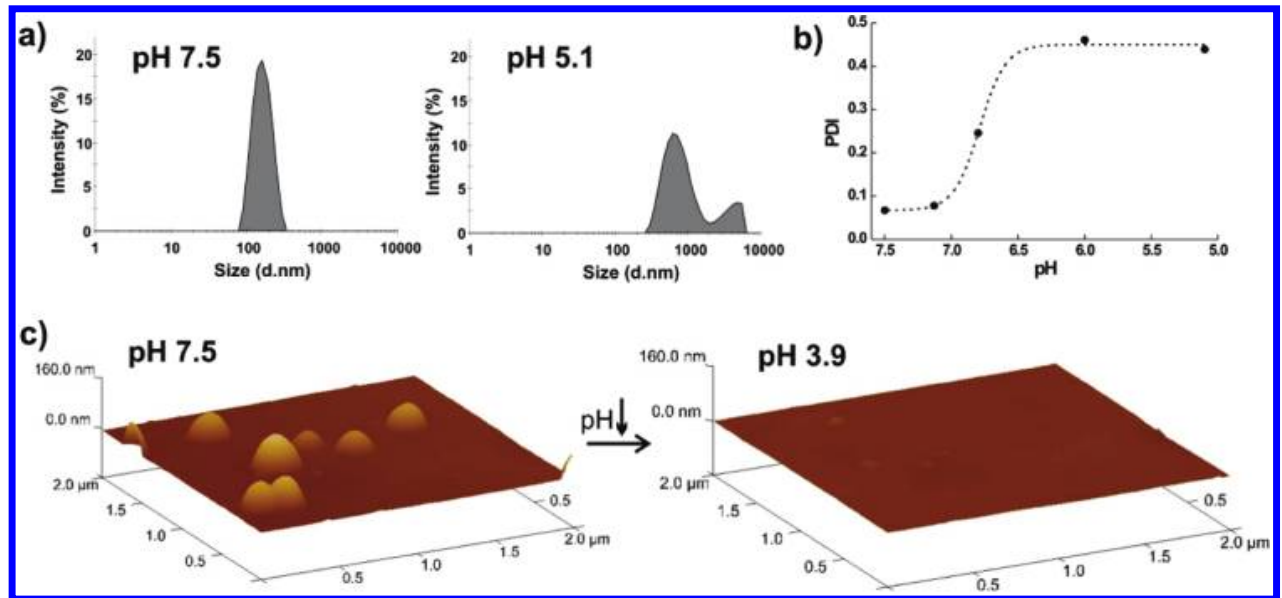

Figure 5. (a) DLS size distribution of TMC/ $\alpha$-GAL PEC0.82 with TPP (TMC/TPP mass ratio: 3.6) in $10 \mathrm{mM}$ HEPES buffer at $\mathrm{pH} 7.5$ and at $\mathrm{pH}$ 5.1. (b) PDI of the same sample as a function of $\mathrm{pH}$. (c) 3D representations of AFM images (height, tapping mode) of TMC/ $\alpha$-GAL PEC0.82 with TPP (TMC/TPP mass ratio: 3.6) on an HOPG substrate in $10 \mathrm{mM}$ HEPES buffer $\mathrm{pH} 7.5$ and after $\mathrm{HCl}$ addition ( $\mathrm{pH} 3.9$ ). The images correspond to the exact same area. The time difference between the capture of the two images is $2 \mathrm{~min}$.

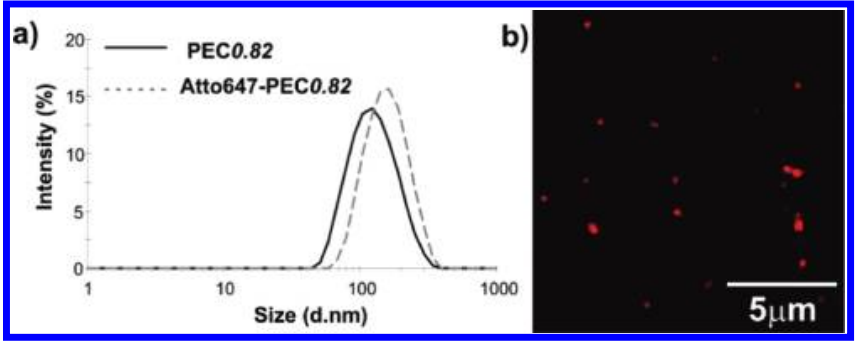

Figure 6. (a) DLS size distribution of a PEC between TMC or TMC/ Atto647N-TMC (70:30) and $\alpha$-GAL in a mass ratio of 0.82 with TPP (TMC/TPP mass ratio: 3.6), in $10 \mathrm{mM}$ HEPES buffer $\mathrm{pH}$ 7.5. For PEC0.82: $D=120.4 \mathrm{~nm}$, PDI $=0.180$; for Atto647N-PEC0.82: $D=$ $145.7 \mathrm{~nm}, \mathrm{PDI}=0.109$. The standard deviation of the average diameter (D) was $11 \mathrm{~nm}$. (b) Wide-field microscopy image of Atto647N-labeled TMC/ $\alpha$-GAL PECs in $10 \mathrm{mM}$ HEPES $\mathrm{pH} 7.5$ at $37^{\circ} \mathrm{C}$.

To track the uptake and distribution of the TMC/ $\alpha-G A L$ PECs in these cells, we first engineered $\alpha$-GAL-containing PECs from TMC previously labeled with Atto 647N. A mixture of unlabeled TMC and Atto647N-TMC solutions (volume ratio of $70: 30)$ was added to the $\alpha$-GAL/TPP solution to obtain the fluorescently labeled PECs. Atto $647 \mathrm{~N}$ concentration in the PEC provided a significant signal for detection by wide-field, confocal fluorescence microscopy, and flow cytometry. Stable and uniform fluorescent TMC/ $\alpha$-GAL PECs could be prepared, taking particle average diameter, PDI, and $\zeta$-potential as assessment parameters. Fluorescently labeled PECs (Atto647N-PEC0.82) presented an average diameter of $145.7 \mathrm{~nm}$ and PDI of 0.109 , as shown in Figure 6a, and $\zeta$-potential value of $19.6 \pm 5.9 \mathrm{mV}$. Single-molecule fluorescence analysis also revealed that PEC nanoparticles were homogeneous in size and did not form aggregates in $10 \mathrm{mM}$ HEPES buffer $\mathrm{pH} 7.4$ (Figure 6b). Moreover, Atto647N-labeled TMC/ $\alpha$-GAL PECs possessed good colloidal stability in both water/HEPES and serum-free cell culture medium. No significant increase in particle size or PDI was evident in medium (data not shown).

The binding and uptake of Atto647N-TMC/ $\alpha$-GAL PECs by HMEC-1 cells was studied by confocal fluorescence microscopy and flow cytometry. We first compared the uptake efficiency of

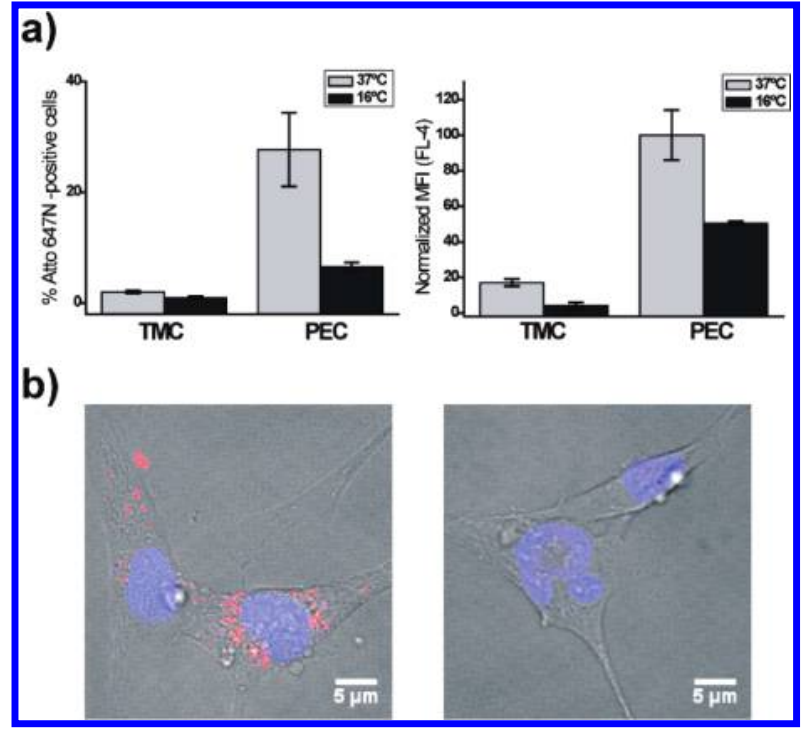

Figure 7. Specific uptake of Atto 647N-labeled TMC/ $\alpha$-GAL PEC0.82 (PEC) or Atto 647N-labeled TMC in live HMEC-1. (a) Flow cytometry quantitation of the fraction of cells that had internalized PECs as the percent (\%) of Atto $647 \mathrm{~N}$-positive cells among the given number of cells counted (left) and mean fluorescence intensity (MFI) of Atto647N in the cells normalized to the maximum fluorescence intensity $(n=3$, mean \pm SD) (right). (b) Confocal fluorescence micrographs of cells incubated with $15 \mu \mathrm{g} \mathrm{mL}{ }^{-1}$ Atto647N-labeled TMC/ $\alpha$-GAL PECs (left panel) or Atto647N-labeled TMC (right panel) for $2 \mathrm{~h}$ at $37{ }^{\circ} \mathrm{C}$, washed, and incubated in fresh medium with Hoechst 33342 for nuclei labeling.

Atto647N-PEC0.82 with that of their precursor, Atto647NTMC. In the absence of an oppositely charged molecule (e.g., $\alpha$-GAL), TMC does not form stable nanoparticles in aqueous media but tends to aggregate in diverse structures heterogeneous in size ranging from $50 \mathrm{~nm}$ to micrometers, as detected by DLS (Supporting Information, Figure S1). We therefore hypothesized that this heterogeneity of these TMC aggregates might prevent its entry into the cells. To test this hypothesis, HMEC-1 cells were incubated with Atto647N-TMC or Atto647N-labeled TMC/ $\alpha$-GAL PECs for $2 \mathrm{~h}$ at $37^{\circ} \mathrm{C}$ at a dose of $15 \mu \mathrm{g} \mathrm{mL}{ }^{-1}$. 


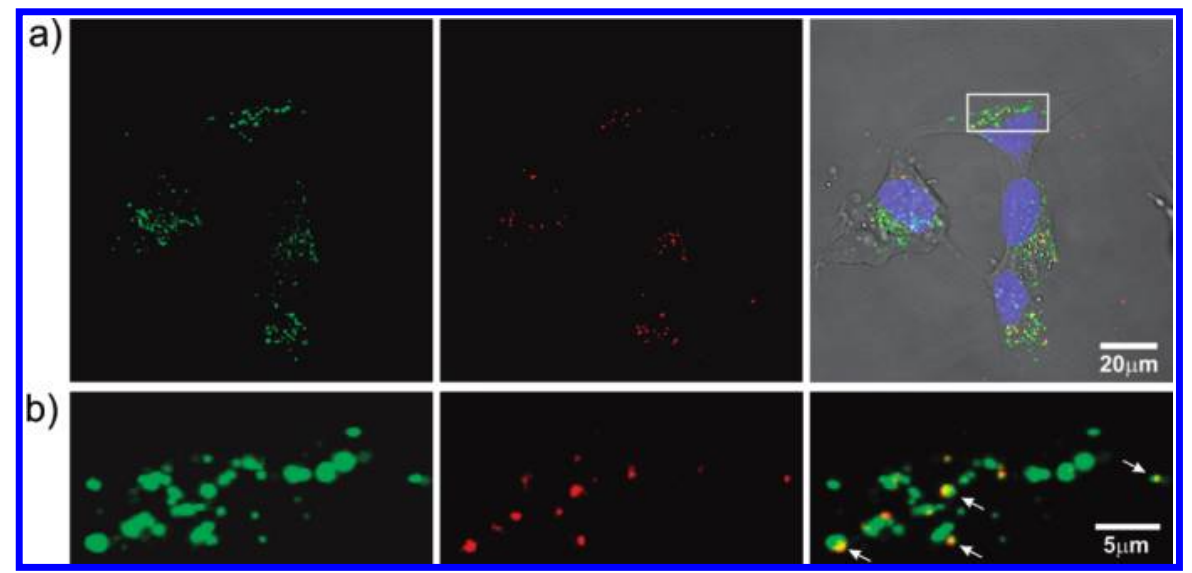

Figure 8. Cellular uptake profile of TMC/ $\alpha$-GAL PECs and colocalization with Lysotracker. Live HMEC-1 cells were incubated with $15 \mu \mathrm{g} \mathrm{mL}^{-1}$ Atto647N-labeled TMC/ $\alpha$-GAL PECs (red) at $37{ }^{\circ} \mathrm{C}$ and $5 \% \mathrm{CO}_{2}$, labeled with lysosomal probe (green) and analyzed by laser scanning confocal microscopy (LSCM). (a) Confocal images showing cellular uptake of HMEC-1 after $2 \mathrm{~h}$ of incubation with TMC/ $\alpha$-GAL PECs. (b) Magnified image of the boxed area (white) in (a) shows some lysosomal compartments filled with Atto647N-labeled TMC/ $\alpha$-GAL PECs. Colocalization of TMC/ $\alpha$-GAL PECs with lysosome appears yellow in merged images and highlighted by arrows.

As shown in Figure 7a (left graph), flow cytometry measurements indicate that $\sim 30 \%$ of the cells showed enhanced fluorescence when incubated with Atto647N-TMC/ $\alpha$-GAL PECs at $37^{\circ} \mathrm{C}$. In contrast, only $\sim 1 \%$ of the Atto647N-TMC-incubated cells were detected by flow cytometry (Figure 7a, left). Furthermore, a decrease in the fraction of positive cells by FACS was observed when cells had been pulsed with TMC/ $\alpha$-GAL PECs at $16{ }^{\circ} \mathrm{C}$, a temperature that precludes endocytosis (Figure $7 \mathrm{a}$ ). Importantly, the mean fluorescence intensity (MFI) values measured for HMEC-1 incubated with Atto647N-labeled TMC/ $\alpha$-GAL PECs were 5 to 6 times higher than those of the cells incubated with Atto647N-TMC (Figure 7a, right).

The enhanced uptake of Atto647N-labeled TMC/ $\alpha-G A L$ PECs by HMEC-1 cells were further verified by confocal fluorescence microscopy. When HMEC-1 was incubated with Atto647N-labeled TMC/ $\alpha-G A L$ PECs for $2 \mathrm{~h}$ at $37^{\circ} \mathrm{C}$, fluorescent red spots were clearly observed inside the cells (Figure $7 \mathrm{~b}$, left panel). Three-dimensional reconstructions of z-stacked images of HMEC-1 evidenced that the fluorescent signal of PECs was indeed inside the cell. However, cells incubated with the Atto647N-TMC barely showed a minimum fluorescence intensity inside the cell (Figure $7 b$, right panel). This suggests that the physicochemical properties of TMC/ $\alpha-G A L$ PECs might facilitate its binding and subsequent uptake into the cells. Physicochemical properties such as particle size, shape, surface charge, and composition play a key role in the cellular uptake of polymeric nanoparticles. ${ }^{37}$ Some relevant studies on the particle size dependency described that smaller particles with a uniform size distribution showed a higher degree of tissue uptake, ${ }^{43}$ which is consistent with our data of PEC uptake by HMEC-1. Therefore, it is tempting to speculate that a uniform size distribution of $\alpha$-GAL/TMC PECs might influence favorably the uptake of these complexes by HMEC-1.

It has been reported that nonspecific cell uptake of nanocarriers occurs by endocytic process. ${ }^{24}$ Our results show that a significant percentage of the cell-associated PECs was distributed within the cells. This internalization of PECs could not be attributed to a disruption of the cell plasma membrane because the dose of PECs used did not alter cell viability, as judged by flow cytometric analysis with propidium iodide (Supporting Information,
Figure S2). Therefore, it is highly likely that the PECs were internalized by adsorptive endocytosis, an energy-dependent process that is preceded by nonspecific interaction of the cargo with the cell membrane. ${ }^{44}$

From the standpoint of other therapies, the lysosomal destination of protein delivery nanocarriers represents a drawback because proteolytic degradation of the cargo reduces duration of the therapeutic effect. However, in the context of ERT for Fabry disease, lysosomal destination of TMC/ $\alpha$-GAL PECs is actually desired. Thus, we investigated whether internalized PECs trafficked to endosomal/lysosomal compartments in live HMEC-1. To that end, we used Lysotracker (green), which is a fluorescent probe that labels and tracks acidic organelles.

Multicolor fluorescence microscopy showed significant colocalization between Atto647-PECs and Lysotracker after only $2 \mathrm{~h}$ of incubation with Atto647-PECs (Figure 8, top panels). Magnified images clearly showed nearly full colocalization of PECs with lysosomes (Figure 8, bottom panels), demonstrating that TMC/ $\alpha$-GAL PECs are internalized by HMEC- 1 and accumulated in lysosomal compartments.

As shown in previous experiments (Figure 5), acid $\mathrm{pH}$ destabilizes the TMC/ $\alpha$-GAL PEC favoring the dissociation between $\alpha$-GAL and TMC and, in turn, optimal conditions for $\alpha$-GAL activity. Then, in the acidic environment of cellular lysosomes, $\alpha-G A L$ is expected to dissociate from the nanoparticle and exert its biological action. Even though the TMC/ $\alpha$ GAL PECs may be previously disrupted in the endosomal compartments ( $\mathrm{pH}$ 5.5) and $\alpha$-GAL dissociated from TMC, the chemical compositions of these nanoconjugates will prevent lysis and potential escape of $\alpha$-GAL from this degradative compartment. Endolysosomal lysis and subsequent escape of contents from this degradative compartment has been reported to occur because of the proton sponge effect caused by polyelectrolytes with high buffer capacity. ${ }^{45-47}$ However, and in contrast with chitosan, TMC has a low buffer capacity for a $\mathrm{pH}$ drop from 7.4 to 5.5 to 4.5 (see Figure 1), thus preventing an increase in the osmolarity of the endolysosomal compartment and, in turn, its subsequent rupture. Therefore, the unique chemical properties of these TMC-based nanoconjugates make 
them the ideal system for delivery of lysosomal proteins in living cells representing highly valuable therapeutic agents for treatment of LSDs, including Fabry disease.

\section{- CONCLUSIONS}

Ionically cross-linked colloidal PECs between TMC and the lysosomal protein $\alpha$-GAL were successfully obtained by selfassembly in a simple way. The physicochemical properties of the obtained PECs have been thoroughly characterized by DLS, AFM, and fluorescence microscopy. A protein LE of $\sim 65 \%$ with a $62 \%$ of specific enzymatic activity was achieved. Following a $\mathrm{pH}$ drop from physiological (around 7.5) to endosomal/lysosomal (4.5 to 5.5) values, the PECs dissociated and released the protein. Finally, a rapid PEC internalization and further accumulation in lysosomal compartments of human endothelial cells was demonstrated. Altogether, our results demonstrate that the $\alpha$-GAL nanocarriers are stable and active under physiological conditions and traffic to lysosomal compartments of human endothelial cells, where the acidic conditions can trigger the release of the protein. As such, this system represents a valuable and promising alternative for lysosomal ERT with improved efficiency in Fabry disease and other LSDs.

\section{ASSOCIATED CONTENT}

S Supporting Information. DLS size distribution of TMC compared with the one of TMC/ $\alpha$-GAL PEC0.82. Effect of TMC/ $\alpha$-GAL PECs on HMEC- 1 cell viability. This material is available free of charge via the Internet at http://pubs.acs.org.

\section{AUTHOR INFORMATION}

\section{Corresponding Author}

*E-mail: migiannotti@ub.edu. Fax: +34 934020183 (M.I.G.).

E-mail: fsanz@ub.edu. Fax: +34 93402123 (F.S.).

\section{ACKNOWLEDGMENT}

Financial support from CIBER-BBN (FABRY project) and Fundació La Marató de TV3 (NanoFabry project) is gratefully acknowledged. CIBER-BBN is an initiative funded by the VI National R\&D\&i Plan 2008-2011, Iniciativa Ingenio 2010, Consolider Program, CIBER Actions and financed by the Instituto de Salud Carlos III with assistance from the European Regional Development Fund. Prof. B. Sarmento (University of Porto, Portugal) and Dr. M. A. Mateos-Timoneda (Institute for Bioengineering of Catalonia IBEC, Spain) are gratefully acknowledged for fruitful discussions. We also thank Dr. J. L. Corchero and Prof. A. Villaverde (UAB, Spain) for providing $\alpha$-GAL, Merche Rivas for her technical assistance with flow cytometry experiments, and Ignaci García Ibáñez, Sonia Matencio, and Cristina Rivero Martí for their technical contributions with synthesis of TMC and characterization of PECs. We acknowledge Dr. Ibane Abasolo for providing the HMEC-1 cell line stock, originally obtained from Dr. E. Ades and Mr. F. J. Candal (Centers for Disease Control and Prevention CDC, Atlanta, GA) and Dr. T. Lawley (Emory University, Atlanta, GA). We are also grateful to Flow Cytometry Unit of the Scientific and Technical Services of the University of Barcelona and the joint CSIC-PCB Advanced Fluorescence Microscopy Unit.

\section{REFERENCES}

(1) Futerman, A. H.; van Meer, G. Nat. Rev. Mol. Cell Biol. 2004, 5, 554-565.

(2) Eng, C. M.; Guffon, N.; Wilcox, W. R.; Germain, D. P.; Lee, P.; Waldek, S.; Caplan, L.; Linthorst, G. E.; Desnick, R. J. N. Engl. J. Med. 2001, 345, 9-16.

(3) Schaefer, R. M.; Tylki-Szymanska, A.; Hilz, M. J. Drugs 2009, 69, 2179-2205.

(4) Beck, M. IUBMB Life 2010, 62, 33-40.

(5) Rombach, S. M.; Twickler, T. B.; Aerts, J. M. F. G.; Linthorst, G. E.; Wijburg, F. A.; Hollak, C. E. M. Mol. Genet. Metab. 2010, 99, 99-108.

(6) Lee, K. Y.; Yuk, S. H. Prog. Polvm. Sci. 2007, 32, 669-697.

(7) Allen, T. M. Adv. Druo Deliverv Rev. 1994, 13, 285-309.

(8) Owens, D. E.; Peppas, N. A. Int. J. Pharm. 2006, 307, 93-102.

(9) Jintapattanakit, A.; Junyaprasert, V. B.; Mao, S.; Sitterberg, J.; Bakowsky, U.; Kissel, T. Int. I. Pharm. 2007, 342, 240-249.

(10) Cohen Stuart, M. A. Colloid Polvm. Sci. 2008, 286, 855-864.

(11) Lankalapalli, S.; Kolapalli, V. R. M. Indian J. Pharm. Sci. 2009, $71,481-487$.

(12) Krishna Sailaja, A.; Amareshwar, P.; Chakravarty, P. Res. J. Pharm. Biol. Chem. Sci. 2010, 1, 474-484.

(13) Calvo, P.; Remuñan-Lopez, C.; VilaJato, J. L.; Alonso, M. J. L. Appl. Polvm. Sci. 1997, 63, 125-132.

(14) Liu, Z.; Jiao, Y.; Wang, Y.; Zhou, C.; Zhang, Z. Adv. Drug Delivery Rev. 2008, 60, 1650-1662.

(15) Sarmento, B.; Ferreira, D. C.; Jorgensen, L.; van de Weert, M. Eur. J. Pharm. Biopharm. 2007, 65, 10-17.

(16) Luppi, B.; Bigucci, F.; Cerchiara, T.; Zecchi, V. Expert Opin. Drug Delivery 2010, 7, 811-828.

(17) Zhang, H.; Oh, M.; Allen, C.; Kumacheva, E. Biomacromolecules 2004, 5, 2461-2468.

(18) Teijeiro-Osorio, D.; Remunan-Lopez, C.; Alonso, M. J. Biomacromolecules 2009, 10, 243-249.

(19) Jayakumar, R.; Menon, D.; Manzoor, K.; Nair, S. V.; Tamura, H. Carbohvdr. Polvm. 2010, 82, 227-232.

(20) Amidi, M.; Mastrobattista, E.; Jiskoot, W.; Hennink, W. E. Adv. Drug Deliverv Rev. 2010, 62, 59-82.

(21) Bayat, A.; Dorkoosh, F. A.; Dehpour, A. R.; Moezi, L.; Larijani, B.; Junginger, H. E.; Rafiee-Tehrani, M. Int. I. Pharm. 2008, 356, 259-266.

(22) Mourya, V. K.; Inamdar, N. N. J. Mater. Sci.: Mater. Med. 2009, 20, 1057-1079.

(23) Verheul, R. J.; Amidi, M.; van der Wal, S.; van Riet, E.; Jiskoot, W.; Hennink, W. E. Biomaterials 2008, 29, 3642-3649.

(24) Dehousse, V.; Garbacki, N.; Colige, A.; Evrard, B. Biomaterials 2010, 31, 1839-1849.

(25) Liu, W. G.; Zhang, X.; Sun, S. J.; Sun, G. J.; Yao, K. D.; Liang, D. C.; Guo, G.; Zhang, J. Y. Bioconiugate Chem. 2003, 14, 782-789.

(26) Thanou, M.; Florea, B. I.; Geldof, M.; Junginger, H. E.; Borchard, G. Biomaterials 2002, 23, 153-159.

(27) Germershaus, O.; Mao, S.; Sitterberg, J.; Bakowsky, U.; Kissel, T. I. Controlled Release 2008, 125, 145-154.

(28) Yin, L.; Ding, J.; He, C.; Cui, L.; Tang, C.; Yin, C. Biomaterials 2009, 30, 5691-5700.

(29) Garman, S. C.; Garboczi, D. N. I. Mol. Biol. 2004, 337, 319335.

(30) Hsu, J.; Serrano, D.; Bhowmick, T.; Kumar, K.; Shen, Y.; Kuo, Y. C.; Garnacho, C.; Muro, S. I. Controlled Release 2011, 149, 323-331.

(31) Sieval, A. B.; Thanou, M.; Kotzé, A. F.; Verhoef, J. C.; Brussee, J.; Junginger, H. E. Carbohvdr. Polvm. 1998, 36, 157-165.

(32) Jiang, X.; van der Horst, A.; van Steenbergen, M.; Akeroyd, N.; van Nostrum, C.; Schoenmakers, P.; Hennink, W. Pharm. Res. 2006, 23, 595-603.

(33) Corchero, J. L.; Mendoza, R.; Lorenzo, J.; Rodríguez-Sureda, V.; Domínguez, C.; Vázquez, E.; Ferrer-Miralles, N.; Villaverde, A. Biotechnol. Prog., in press. DOI: 10.1002/btpr.637.

(34) Moghimi, S. M.; Hunter, A. C.; Murray, J. C. FASEB J. 2005, $19,311-330$. 
(35) He, C.; Hu, Y.; Yin, L.; Tang, C.; Yin, C. Biomaterials 2010, $31,3657-3666$.

(36) Rejman, J.; Oberle, V.; Zuhorn, I. S.; Hoekstra, D. Biochem. J. 2004, 377, 159-169.

(37) Chavanpatil, M. D.; Khdair, A.; Panyam, J. J. Nanosci. Nanotechnol. 2006, 6, 2651-2663.

(38) Panyam, J.; Labhasetwar, V. Adv. Drug Delivery Rev. 2003, 55, 329-347.

(39) Amidi, M.; Romeijn, S. G.; Borchard, G.; Junginger, H. E.; Hennink, W. E.; Jiskoot, W. L. Controlled Release 2006, 111, 107-116.

(40) Janes, K. A.; Alonso, M. J. J. Appl. Polym. Sci. 2003, 88, 2769-2776.

(41) Csaba, N.; Koping-Hoggard, M.; Alonso, M. J. Int. J. Pharm. 2009, 382, 205-214.

(42) Ades, E. W.; Candal, F. J.; Swerlick, R. A.; George, V. G.; Summers, S.; Bosse, D. C.; Lawley, T. J. J. Invest. Dermatol. 1992, 99, 683-690.

(43) Desai, M. P.; Labhasetwar, V.; Amidon, G. L.; Levy, R. J. Pharm. Res. 1996, 13, 1838-1845.

(44) Raub, T. J.; Audus, K. L. L. Cell Sci. 1990, 97, 127-138.

(45) Behr, J.-P. Chimia 1997, 51, 34-36.

(46) Funhoff, A. M.; van Nostrum, C. F.; Koning, G. A.; SchuurmansNieuwenbroek, N. M. E.; Crommelin, D. J. A.; Hennink, W. E. Biomacromolecules 2004, 5, 32-39.

(47) Mateos-Timoneda, M. A.; Lok, M. C.; Hennink, W. E.; Feijen, J.; Engbersen, J. F. I. ChemMedChem 2008, 3, 478-486. 